DOI:

\title{
INTERACTIVE FORMS OF LEARNING AS A WAY TO OPTIMIZE THE LEARNING PROCESS
}

\author{
Ignatova Valentina Vladimirovna \\ Senior Lecturer \\ Skripnik Larisa Viktorovna \\ Senior Lecturer \\ Kharkiv national University of construction and architecture \\ (Kharkiv, Ukraine ) \\ e-mail: vignatova594@gmail.com \\ scripnick.larisa@yandex.ua
}

\begin{abstract}
The article discusses interactive forms and methods of teaching Russian to foreign students. The basics of the theory of active learning are presented, as well as methods for creating and using mind maps, case method and role-playing games. The authors propose to expand the possibilities of applying these methods, to involve the students themselves in the process of creation, developing their analytical and creative abilities for the rapid assimilation of new material. Interactive learning is based on the principles of dialogical interaction, work in small groups on the basis of cooperation and cooperation, active role (play) activities, training organization of training. The introduction of interactive methods contributes to the formation of the communicative competence of students, increasing the motivation of students, the development of cognitive activity, skills of joint activity and much more. These methods give the teacher the opportunity to improve professional knowledge and skills
\end{abstract}

Keywords: optimization of the educational process, interactive forms of education, communicative competence, role-playing games, case method, mind maps, cognitive activity

\section{ИНТЕРАКТИВНЫЕ ФОРМЫ ОБУЧЕНИЯ КАК СПОСОБ ОПТИМИЗАЦИИ УЧЕБНОГО ПРОЦЕССА}

\author{
Игнатова Валентина Владимировна \\ Старший преподаватель \\ Скрипник Лариса Викторовна \\ Старший преподаватель \\ Харьковский национальный университет \\ строительства и архитектуры \\ (Харьков,Украина) \\ e-mail: vignatova594@gmail.com \\ scripnick.larisa@yandex.ua
}

Аннотация. В статье рассматриваются интерактивные формы и методы обучения на занятиях по русскому языку как иностранному. Представлены методы создания и использования интеллект-карт, кейс-метода и ролевых игр. Авторами предлагается расширять возможности применения данных методов, привлекать к процессу создания самих учащихся, развивая их аналитические и творческие способности для быстрого усвоения нового материала. Интерактивное обучение основывается на принципах диалогического взаимодействия, работы в малых группах на основе кооперации и сотрудничества, активной ролевой (игровой) деятельности, 
тренинговой организации обучения. Внедрение интерактивных методов способствует формированию коммуникативной компетентности студентов, повышению мотивации учащихся, развитию познавательной активности, навыков совместной деятельности и многому другому. Преподавателю данные методы дают возможность совершенствовать профессиональные знания и мастерство.

Ключевые слова: оптимизация учебного процесса, интерактивные формы обучения, коммуникативная компетенция, ролевые игры, кейс-метод, интеллект-карты, познавательная активность.

\section{ВВЕДЕНИЕ}

Использование интерактивных форм обучения на занятиях по русскому языку как иностранному позволяет оптимизировать учебный процесс. Положительной стороной включения в работу интерактивных форм обучения является повышение уровня мотивации к изучению дисциплины, активное вовлечение каждого студента в учебный процесс, эффективное закрепление и понимание учебного материала, формирование навыков самостоятельной работы, развитие критического мышления, создание комфортной атмосферы на занятии. Недостатком этого процесса является трудоемкость подготовительного этапа для преподавателя, поскольку значительное количество времени необходимо потратить на подготовку к занятиям такого рода, внимательно выверить подготовленный материал. И, безусловно, не последнее место занимают субъективные факторы.

Интерактивное обучение предполагает моделирование жизненных ситуаций, использование игровых форм, совместное решение проблем.

Интерактивная деятельность также предполагает организацию и развитие диалогового общения, которое ведет к взаимопониманию, взаимодействию, к совместному решению общих, но значимых для каждого участника задач. Интерактивное обучение исключает доминирование как одного выступающего, так и одного мнения над другим (Makhotin, 2013).

\section{ОБЗОР ЛИТЕРАТУРЫ}

Впервые понятие «интеракция» появилось в психологии и социологии. Идеи теории символического интеракционизма (Дж. Г. Мид (США), Г. Блумер (США), Д.М. Болдуин (США), Ч. Кули (США) и др. стали базой для развития такого направления в методике, как интерактивные методы и средства обучения. Впоследствии проблема освоения и использования интерактивных методов обучения нашла свое отражение в работах Д.И. Кавтарадзе,

М.В. Кларина, А.В. Хуторского, Д.А. Махотина и др.

В настоящее время понятие "интерактивные методы обучения" наполняется новым содержанием, приоритетная роль в нем отводится: взаимодействию (П.Д. Гаджиева, Д.И. Кавтарадзе, М.В. Кларин, Т.А. Мясоед, Б.Ц. Бадмаев); развитию навыков общения личности (Л.К. Гейхман, Л.В. Зарецкая, Д.А. Махотин); развитию и осуществлению социального опыта людей (Л.Н. Куликова); учебно-педагогическому сотрудничеству между участниками образовательного процесса (Е.В. Коротаева, А.Ю. Прилепо, Н.Е. Щуркова и др.). Вместе с тем, проблема использования интерактивных методов как фактора самореализации студентов в учебной деятельности недостаточно исследована.

\section{МЕТОДЫ ИССЛЕДОВАНИЯ}

Самореализация учащихся в учебной деятельности возможна с помощью различных способов и методов. Большое значение в современной науке отводится интерактивным методам обучения, так как они ориентированы на активную совместную учебную деятельность, общение, взаимодействие 
учителя и учащихся и позволяют выстроить образовательное пространство для самореализации учащихся (Clarin 2000). В связи с этим особенно важно уделить должное внимание отбору и использованию таких образовательных методов и технологий, которые резко повышают качество процесса обучения, делают его более производительным, действенным и результативным (Stupina 2009). Остановимся на некоторых из них.

На подготовительном факультет и на первом курсе весьма эффективно использование ролевых игр, что создает оптимальные условия для свободного самовыражения личности, поскольку она предусматривает открытость, которая разворачивается в виде изображения определенных жизненных ситуаций и состояний личности (Kavtaradze 2009).

Например, уже при завершении вводно-фонетического курса на итоговом занятии по теме «Моя семья», легко отрабатываются следующие грамматические конструкции: «Меня (его, ее) зовут ...», «Мне (ему, ей) ... год/года/лет», «Я (он, она) ... (профессия, род занятий)», «Это мой отеи (папа)/моя мать (мама)/ мой брат/моя сестра/мой сын/моя дочь», затем активнее и лексически насыщеннее проходят занятия по темам «Мой родной город - это ...», «Город, где я учусь - это ...». Актуализируется и закрепляется материал, связанный с употреблением количественных числительных, личных и притяжательных местоимений, с категорией рода в русском языке. Чаще всего иностранные студенты охотно вовлекаются в такую игру, так как обучение профильным предметам на подготовительном факультете осуществляется традиционными методами.

На подготовительном факультете после введения нового материала перед преподавателем стоит задача сформировать устойчивые речевые навыки. Опять-таки, ориентируясь на уровень подготовленности студентов группы, преподаватель распределяет между ними роли одного из героев книги, фильма или мультфильма, информация о которых собирается преподавателем заранее. Задача каждого студента - создать «визитную карточку» своего героя с использованием только что изученного лексико-грамматического материала. Отрабатывая навыки построения собственного монологического высказывания, у студентов формируется способность вступать в коммуникацию. «Визитная карточка» каждого из героев должна стать результатом подготовки ответов на ряд заранее подготовленных преподавателем вопросов. Родным городом каждого из героев становится как столица его родной страны, так и другая страна, что в дальнейшем послужит материалом для формирования лексико-грамматических навыков, связанных с употреблением имён прилагательных. Итогом работы по созданию «визитной карточки» каждого из героев становится монологическое высказывание с использованием изученного языкового материала. Развитие коммуникативных умений в этом случае происходит в результате диалога каждого из героев с группой. Особо акцентируя внимание студентов на универсальности изучаемых моделей, а затем (в «сильных группах») предлагается создать «визитную карточку» виртуального героя или использовать лексическо-грамматический материал, не представленный на занятии. Например, в группе появляется Натали (она архитектор, её родная страна - Франция) или Сяо (он инженер, его родная страна - Китай). Интерактивные технологии подобного рода направлены на развитие критического мышления студентов, активизацию их познавательной и ментальной деятельности, то есть осмысленное восприятие и последующее усвоение информации, позволяющее сформировать картину мировосприятия.

На подготовительном факультете, а также со студентами второго курса очень успешно был опробован и кейс-метод или метод конкретных ситуаций - метод активного проблемноситуационного анализа, основанный на обучении путем решения конкретных задач - ситуаций.

Задача кейса - исследовать предложенную ситуацию, которая представляет не только практическую проблему, но и требует подключения ранее усвоенных знаний, необходимость сформулировать проблему и определить четкий сценарий ее разрешения. А необходимость аргументировать свою точку зрения, анализировать выступление одногруппников и 
выслушивание противоположных позиций учит студентов работать в команде, развивая коммуникативную компетенцию. А если в группе учатся студенты из разных стран, для которых русский язык - единственный способ и инструмент общения, то это усиливает позитивную мотивацию.

На подготовительном факультет мы рассматривали проблему полезности и вредности пищевых продуктов для молодого организма, выбирали лучшего участника песенного конкурса. А на втором курсе кейс-метод очень помог при изучении темы «Икона и иконопись».

И поскольку очень напряженная учебная деятельность предполагает переключение внимания, иногда мы используем ещё один прием технологии критического мышления, разработанный американским ученым и психологом Бенджамином Блумом. Прием называется "Кубик Блума". И если раньше этот прием использовался исключительно на подготовительном факультете, то в последнее время и студенты 2-3 курсов получают удовольствие, когда кубик Блума присутствует на уроке. И при закреплении грамматических тем, и при подведении итогов тем страноведческих он очень выручает, с одной стороны, внося игровой момент в скучную тему урока, а с другой стороны, закрепляет коммуникативные знания, поскольку приобретение коммуникативной компетенции, получение образования в нашей стране на неродном языке для иностранного студента является движущей силой, создающей понимание того, что приобретенные умения позволят правильно понимать, общаться и действовать в условиях современной культурной ситуации.

Еще одним интерактивным методом, который используется при изучении языка, являются интеллект-карты. Карты памяти используются для создания, визуализации, структурирования и классификации любого материала, а также как средство обучения.

Впервые об интеллект-картах заговорили еще в 70-х годах прошлого века, а автором идеи стал известный психолог Тони Бьюзен. Бьюзен разработал уникальную технологию осмысления и запоминания информации, которую впоследствии назвал интеллект-картой.

Интеллект-карта предлагает такой способ организации информации, чтобы мозгу было максимально легко работать с ней. С помощью этой технологии, можно научиться мыслить совершенно по-новому, используя потенциал обоих полушарий мозга.

Почему запись в виде интеллект-карты удобнее и полезнее? Все дело в особенностях нашего мышления. Наше мышление не организовано как текст, линейно. Оно имеет именно такую структуру: разветвленную, то есть в виде веток. Каждое понятие в нашей голове связано с другими понятиями, эти другие понятия связанные с третьими и так далее до бесконечности. Такая организация материала называется многомерной, радиантной. Эта структура наиболее органично отражает наше реальное мышление.

Именно так физически соединяются нейроны в нашем мозге: каждый нейрон опутывает сеть дендритов других нейронов, от одного нейрона по цепям связей мы можем перейти к другому нейрону.

Интеллект-карты позволяют более качественно отобразить структуру материала, смысловые и иерархические связи, показать, какие существуют отношения между составными частями.

В интеллект-карте есть еще один замечательный эффект. За счет своей расширяемости и приспособленности к нашему мышлению, создание интеллект-карт способствует развитию потока ассоциаций, мыслей, идей.

Первые интеллект-карты создает преподаватель, объясняя студентам алгоритм действий. Начинать нужно с небольших и простых карт, показывая этапы создания.

Как создать интеллект-карту? 
Для начала работы понадобятся альбомные листы (или даже ватман, если замысел масштабный), а также карандаши, фломастеры или краски - можно использовать что-то одно, а можно все сразу.

1. Надо четко определить основную тему или проблему - она и будет центральным элементом карты. Ее можно записать словами, а можно подобрать яркий графический образ, ассоциирующийся с выбранной тематикой.

2. От центра выведите несколько ветвей, каждая из которых обозначьте ключевым словам, названиям разделов, связанных с основной темой. Форма ветвей - прямые или волнистые значения не имеет.

3. От каждой из основных ветвей будут отходить дополнительные ветви 2-го, 3-го уровней. Желательно, чтобы они были меньше и тоньше от основных. Главное - помнить, что человеческий мозг не сможет воспринять и запомнить более семи основных ветвей. Это базовое правило при составлении грамотной интеллект-карты. Почему 7? Эта закономерность «семь плюс-минус два» была обнаружена американским учёным-психологом Джорджем Миллером и показывает, что кратковременная память человека способна запоминать в среднем:

- девять двоичных чисел;

- восемь десятичных чисел;

- семь букв алфавита;

- пять односложных слов. Это число также называют числом Ингве-Миллера.

4. Важно соблюдать радиальную структуру. Ветвей и ответвлений может быть столько, сколько нужно, но важнейшие понятия должны располагаться ближе к центру, а менее значимые подальше.

Чтобы не запутаться, можно нумеровать ветви, используя различные цвета для отдельных зон или разные стили рисования. Чем больше цветов будет использовано, тем лучше. Это помогает целостному и структурированному восприятию.

5. Связанные информационные блоки лучше сочетать, выделяя одинаковым цветом или фоном.

6. Не надо расписывать каждое понятие, лучше использовать ключевые слова или вообще символические изображения. Так вы сможете запомнить основную информацию быстрее и легче. Иногда ментальная карта вообще может целиком состоять из рисунков.

Впоследствии каждый из студентов выработает свой собственный стиль рисования интеллект-карт, но в начале эти правила очень пригодятся. Кстати, те, кто не имеет таланта к рисованию, могут воспользоваться онлайн-сервисами для создания интеллект-карт: их очень много, и они действительно удобны. Concept draw, Mind Manager.

Но создавать карты лучше руками - это хороший способ потренировать свое мышление, фантазию. То, что ты создал сам, продумал, проговорил, прописал, лучше усваивается и запоминается.

В методике преподавания языка можно активно используют интеллект-карты для ввода или закрепления грамматического или лексического материала.

Приведем некоторые примеры интеллект-карт, используемых на занятиях по обучению языку на начальном этапе.

Первая представленная интеллект-карта называется «Город». Используется в самом начале обучения, в конце вводно-фонетического курса.

Рис. 1. 


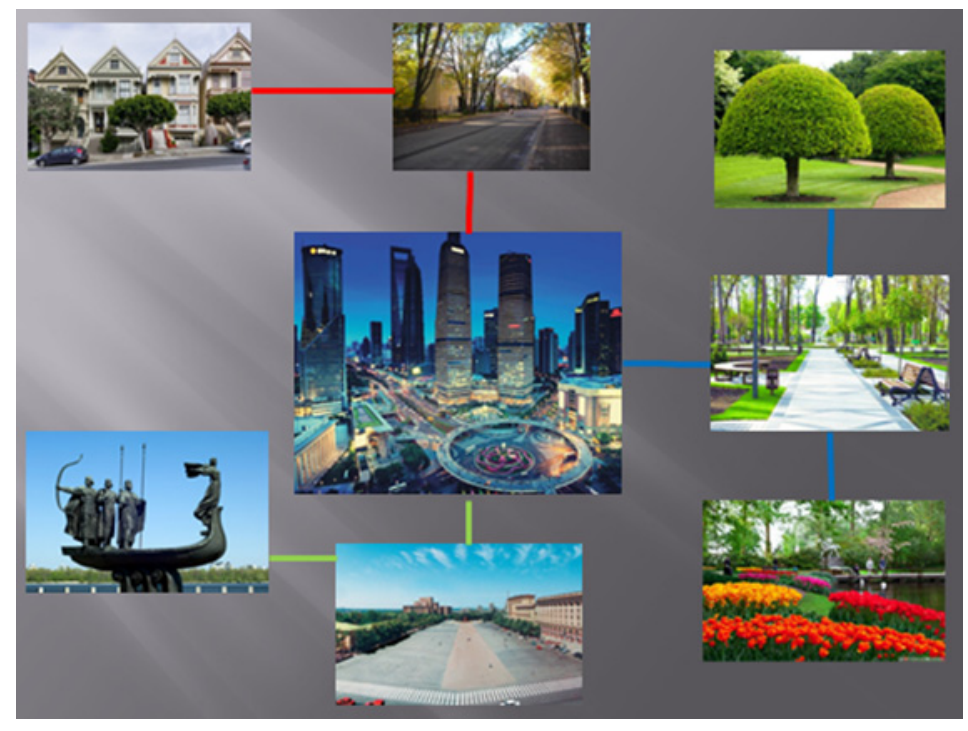

Преподаватель в центре помещает иллюстрацию города, а дальше задает вопрос: Что находится в городе? Студенты, используя выученную лексику, отвечают: улица, площадь, парк. Преподаватель рисует три луча и к каждом лучу прикрепляет соответствующую иллюстрацию.

Преподаватель, показывая на улицу, спрашивает:

- Что находится там?

- Дом, дома.

- Это площадь. Что находится там?

- Памятник.

- Это парк. Что находится там?

- Дерево, деревья. Цветы.

Следующая интеллект-карта - «Предложный падеж».

Рис. 2

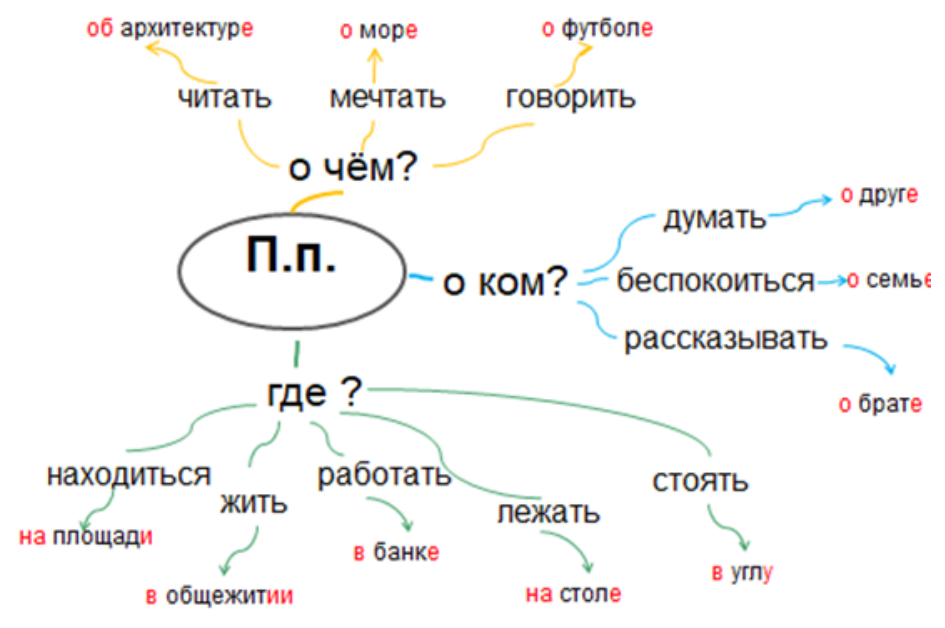

Данную интеллект-карту целесообразно использовать после изучения этого падежа. Карта может быть хорошим средством обобщения и систематизации изученного материала. Преподаватель предлагает студентам приготовить ручки или фломастеры разных цветов, пишет в центре доски концепт интеллект-карты - предложный падеж. Студенты делают это в своих тетрадях. Так как материал уже был изучен ранее, преподаватель не дает студентам готовых ответов и не 
изображает для них готовую интеллект-карту на доске, а с помощью наводящих вопросов просит самих студентов изобразить карту.

Первый вопрос, на который должны ответить студенты: «Какие вопросы предложного падежа вы знаете?». Затем студенты вместе с преподавателем выводят три луча в сторону от концепта в соответствии с количеством вопросов. Дальше преподаватель спрашивает: «Какие глаголы отвечают на вопрос где?» Студенты должны ответить: «жить, находиться, работать, стоять, лежать и т.д.». Преподаватель выводит еще лучи и записывает глаголы.

Далее:

- Где находится памятник?

- На площади.

- Где живут студенты?

- В общежитии.

- Где работает экономист?

- В банке и т. д.

Преподаватель записывает примеры, выделяя при этом окончания и предлоги.

Таким образом, по аналогии изображается вся интеллект-карта. Как только студенты понимают, как выполнять этот вид работы, они начинают делать это самостоятельно, а преподаватель лишь контролирует процесс. В итоге мы получаем справочный материал склонение существительных в предложном падеже, к которому студенты всегда могут обратиться при необходимости.

Заметим, что созданием интеллект-карт может заниматься не только преподаватель, готовя визуальные материалы для объяснения новой грамматической темы или ее закрепления, но и сам студент. Например, в качестве одного из вариантов заданий, которые предлагаются студенту для самостоятельного выполнения, может полностью выступить разработка ментальной карты по выбранному преподавателем грамматическому правилу. В подобном типе домашнего задания есть много преимуществ. От преподавателя требуется в этом случае четкая постановка цели данной задачи с презентацией образцовых вариантов интеллект-карт и подробным объяснением алгоритма их создания.

\section{РЕЗУЛЬТАТЫ И ДИСКУССИЯ}

Использование интерактивных форм на всех этапах обучения позволяет студентам быстрее наладить контакты в группе, выработать чувство коллективизма, а также личной ответственности, улучшить память, создать благоприятную атмосферу на занятии, сформировать необходимые речевые навыки, достаточные для общения в определенных коммуникативных ситуациях. Каждый студент пытается самостоятельно управлять своей монологической и диалогической речью. Интерактивные формы обучения помогают облегчить восприятие и усвоение учебного материала; и в результате повышается уровень мотивации к изучению русского языка как иностранного. Конечно же, включая различные интерактивные формы обучения, преподаватель ориентируется на уровень подготовки группы, её «сработанность».

Кейс-метод обеспечивает более эффективное усвоение материала за счет высокой эмоциональной вовлеченности и активного участия обучаемых. Участники погружаются в ситуацию с головой: у кейса есть главный герой, на место которого ставит себя команда и решает проблему от его лица. Акцент при обучении делается не на овладение готовым знанием, а на его выработку.

Ролевые игры помогают в формировании речевых навыков. Вовлеченность в игру и личная сопричастность к происходящему позволяют активно включаться в беседу даже тем студентам, 
которые обычно немногословны. Постепенно речь становится более уверенной, беглой и разнообразной.

Позволяют пополнять лексический запас. Именно регулярное использование слов приводит к их хорошему освоению. Игровая ситуация способствует активизации памяти, поэтому лексика запоминается еще лучше.

Тренируют восприятие речи на слух. Взаимодействуя с другими участниками игры, можно научиться понимать русскую речь с разными акцентами и произносительными особенностями.

Способствуют общему развитию студента. Ролевые игры на русском не только позволяют совершенствовать языковые умения, но и активизируют творческие способности, навыки ведения диалога и т.д.

Делают обучение более интересным, а значит, и более эффективным.

Дают стимул к обучению. Игры показывают, как изучаемый материал может использоваться в реальных ситуациях. Это позволяет повысить мотивацию.

Создавая интеллект-карты, студент размышляет над удачным системным расположением лексико-грамматических элементов, лучше будет усваивать данный ему для изучения материал, скорее запоминать новую информацию, научится структурировать материал, видеть логику связей различных единиц, находить новые идеи и развивать ассоциативное мышление.

\section{ЗАКЛЮЧЕНИЕ}

Обобщая результаты использования интерактивных форм обучения, можно прийти к выводу, что данные методы позволяют делать процесс обучения более мотивированным, продуктивным, эмоционально насыщенным, личностно-развивающим, а, следовательно, более качественным. Эффект от интерактивных методов, кроме решения образовательных задач, заключается еще и в том, что у студентов развиваются такие навыки, как умение слушать, задавать вопросы и отвечать на них, умение разрешать возникающие проблемы, преодолевать свои комплексы и барьеры.

\section{REFERECES}

Kavtaradze, D.N (2009). Obuchenie i igra: vvedenie v interaktivnye metody obucheniya [Learning and Play: An Introduction to Interactive Teaching Methods]. Moskva: Prosveshcheniye.

Klarin, M.V. (2000). Interaktivnoye obucheniye - instrument osvoeniya novogo opyta. [Interactive learning is a tool for mastering new experiences]. Pedagogika, (7), p.p.12-18.

Makhotin, D.A. (2013). Interaktivnoye obuchenie na urokach ekonomiks.[Interactive learning in economics lessons].Elektronny resurs. http://www.eidos.ru/iournal/

Khutorskoy, A.B. (2005). Menidika lichnostno-orientirovannogo obucheniya. Kak obuchat vsekh poraznomu? [Personality-oriented learning methodology. How do you teach everyone differently?]. Moskva: VIADOS-PRESS.

Stupina S. B. (2009). Technologii interaktivnogo obucheniya $\mathrm{v}$ vyshey shkole. [Technologies of interactive teaching in higher education]/ Saratov: Nauka.

\section{For citation:}

Ignatova, V. \& Skrypnyk, L. (2020). Interactive forms of learning as a way to optimize the learning process // International Scientific-Pedagogical Organization of Philologists " WEST-EAST " (ISPOP). Scientific Journal "WEST-EAST". Vol. 3, N1 (October, 2020). pp. doi: 


\section{Для цитирования:}

Игнатова, В. В., Скрипник, Л. В. (2020) Интерактивные формы обучения как способ оптимизации учебного процесса // International Scientific-Pedagogical Organization of Philologists "WEST-EAST" (ISPOP). Scientific Journal "WEST-EAST". Vol.3, N1 (October, 2020). c. . doi:

\section{Information about the authors:}

Skrypnyk Larisa - Senior lecturer of the Department of Ukrainian Language and Language Training of Foreign Citizens, Kharkov National University of Construction and Architecture, Kharkov, Ukraine. e-mail: scripnick.larisa@yandex.ua

Ignatova Valentina - Senior lecturer of the Department of Ukrainian Language and Language Training of Foreign Citizens, Kharkov National University of Construction and Architecture, Kharkov, Ukraine. e-mail: olga.tesalovskaya@ukr.net

\section{Сведения об авторах:}

Игнатова Валентина Владимировна - старший преподаватель кафедры украинского языка и языковой подготовки иностранных граждан, Харьковский национальный университет строительства и архитектуры, Харьков, Украина.

e-mail: olga.tesalovskaya@ukr.net

Скрипник Лариса Викторовна - старший преподаватель кафедры украинского языка и языковой подготовки иностранных граждан, Харьковский национальный университет строительства и архитектуры, Харьков, Украина.

e-mail: scripnick.larisa@yandex.ua

Manuscript received: 13/08/2020

Accepted for publication: $14 / 09 / 2020$

Рукопись получена: 13/08/2020

Принята к печати: 14/09/2020 